\title{
AN EFFECT OF THE ANIMAL CONDITION AFTER GAS STUNNING ON QUALITY OF SLAUGHTER PRODUCTS FROM LARGE WHITE PIGS
}

Anastasia A. Semenova*, Alena I. Sinichkina, Ilya V. Kozyrev, Tatyana M. Mittelstein

V. M. Gorbatov Federal Research Center for Food Systems of Russian Academy of Sciences, Moscow, Russia

Keywords: $\mathrm{CO}_{2}$ stunning, physiological conditions of pigs, internal organs, meat quality, $\mathrm{pH}$ value, moisture holding capacity

\begin{abstract}
The aim of the research was to establish an effect of gas stunning of pigs at slaughter on the condition of the internal organs and pork functional-technological characteristics. The experiment was carried out in the conditions of the operating enterprise on 37 Large White pigs. When using 94\% concentration in a chamber, only 65\% of animals were assessed as normally stunned, 30\% of animals did not have cardiac activity and were considered dead, 5\% of animals retained sensibility. Assessment of the condition of the internal organs, dynamics of $\mathrm{pH}$ changes, comparison of moisture holding capacity and color characteristics did not reveal substantial and statistically significant differences between slaughter products from normally stunned animals and animals died during stunning. The authors discuss mortality of animals before the beginning of bleeding as a possible cause of similar results of investigation of the internal organs and meat quality from animals with and without cardiac activity after gas stunning.
\end{abstract}

\section{Acknowledgment}

The authors thank the management and specialists of LLC "Ishimsky meat-processing plant» for assistance in carrying out the experiment.

\section{Introduction}

Today in Russia, more than $50 \%$ of pigs sent to slaughter are subjected to gas stunning. This technological operation affects the physiological conditions of animals and can significantly contribute to formation of slaughter product quality, including pork in carcasses and by-products.

From the perspective of animal welfare assurance, the international practice prescribes using high carbon dioxide concentrations (more than $80 \%$ ) [1]. When pigs are placed in a chamber with a concentration of $80-90 \% \mathrm{CO}_{2}$, the loss of consciousness and sensibility is not instantaneous and occurs during $30 \mathrm{sec}$. At such a high $\mathrm{CO}_{2}$ concentration, the duration of the anesthetic effect and unconsciousness of animals increases, and as a consequence, the time interval for performing other slaughter manipulations can be increased.

Unconsciousness is a state of unawareness (loss of consciousness), in which temporal or permanent damage of brain function occurs, when an animal cannot respond to normal stimuli including pain. An animal is considered insensible when it does not show any reflexes or reactions to stimuli such as sound, odor, light or physical contact [1,2]. The use of $\mathrm{CO}_{2}$ stunning implies the unconscious condition with retention of cardiac activity in an animal from the moment of its unloading from a stunning chamber until the end of bleeding.

However, at concentrations higher than 30\%, this gas causes aversion in animals, irritation of the mucous membranes, painful sensations, lung hyperventilation and gasping before loss of consciousness [3]. In several cases, these sensations can provoke the spontaneous development of stress in pigs up to cessation of cardiac activity. From the perspective of the animal slaughter technology for producing meat and by-products, cessation of cardiac activity can lead to incomplete bleeding of a carcass and consequently to a decrease in quality of slaughter products $[4,5]$. In the context of physiology, death is a state of an animal, when respiration and blood circulation have ceased. In the context of using stunning at slaughter, the main clinical signs of death are absence of breathing, absence of pulse and pupil dilation [2].

Despite the wide practice of using gas stunning in the world and international documents stipulating regular monitoring of the process and animal condition [1], any recommendations on the control of the number of animals died during stunning are absent. Nevertheless, it is acknowledged that meeting criteria such as absence of reactions in animals can be linked with complete cessation of cardiac activity [2].

A result of gas stunning is influenced by many factors including individual characteristics of animals determined by a breed and keeping conditions. Modern techniques and technologies of gas stunning used in Russian enterprises are foreign developments. In this connection, scientific research aimed at studying an effect of gas stunning on quality of slaughter products from domestic production are of high topicality, especially regarding breeds such as Large White that are traditionally raised in our country. Although recently a reduction in the number of pig breeds has been observed in Russia, Large White breed remains to be the main (52\%) part of the stock of breeding animals raised on an industrial scale [6]. 
The aim of this study was detection of possible deviations in quality of slaughter products depending on the physiological condition of Large White pigs after gas stunning.

\section{Materials and methods}

The experiment was carried out on Large White pigs $(\mathrm{n}=37)$ at the age of 160 days, raised in a selection center and transported to the place of the experiment in one road vehicle. The distance of transportation was $6.3 \mathrm{~km}$. After 3 hours of resting in the enterprise, pigs were sent to slaughter.

Pigs were exposed to carbon dioxide in a chamber Banss (Germany) with five pigs per chamber. The carbon dioxide concentration was $90 \%$, time of exposure was $115 \mathrm{sec}$. After unloading pigs from a chamber, the result of animal stunning was determined, recording one of the following variants of the physiological condition: norm, retention of sensibility (insufficient effect of stunning), animal death.

A stunning result was considered normal if pigs retained cardiac activity and at the same time did not have signs of sensibility, which corresponds to the requirements of the Technical Regulation TR CU034/2013 «On meat and meat product safety» and international norms. The heart rate (HR) was recorded using a veterinary pulse oximeter DIXION Storm 5000 vet (Dixion, China), attaching a sensor to the ear of an animal after the exit from a gas stunning chamber.

A result of stunning was considered insufficient if animals showed the sings of sensibility (including attempts to stand up and/or raise head, ear movements, vocalization, rhythmic breathing, eye movement and pupil reaction, response to prick).

The animal death was recorded when cardiac activity was absent. A conclusion about absence of cardiac activity was made after triplicate pulse measurements using a pulse oximeter. With that, each time a sensor was fixed at a different point of an ear to exclude a measurement error due to surface contamination of skin or absence of a large vessel in the area of sensor fixation.

At the following stage of the experiment, the internal organs (heart, lung, liver) were examined by assessing a degree of blood filling of tissues and vessels, presence of blood clots in the cardiac chambers and for lungs, additionally, hemoaspiration.

A degree of blood filling of the internal organs was classified as follows:

- normal or insignificant: when pressing a tissue cut, blood does not appear, blood filling is visually observed on a tissue cut only in the individual areas;

- medium: blood filling is visually detected on a tissue cut; when pressing a tissue cut, blood appears; blood vessels are filled with blood;

- high: significant blood filling is visually detected on a tissue cut; blood runs out without pressing; blood vessels are significantly filled with blood.

After primary processing, carcasses were chilled to a temperature not higher than $4{ }^{\circ} \mathrm{C}$ for 24 hours using the classical chilling technology.
Pork $\mathrm{pH}$ and temperature were measured in the hot and chilled state $45 \mathrm{~min}$. and 24 hours after slaughter in $m$. longissimus dorsi between the 5th and 6th thoracic vertebrae in a half-carcass using a pH-meter Testo 205 (Testo, Germany). During measurements, an electrode was placed into muscle tissue at a depth of not less than $3 \mathrm{~cm}$. Arithmetic mean of three single measurements was taken as the final result, divergence between ultimate values of three measurement results was not higher than $0.15 \mathrm{pH}$ units.

Samples of $m$. L. dorsi (about $300 \mathrm{~g}$ ) were taken from chilled half-carcasses 24 hours after slaughter for further laboratory analyses.

Drip losses were determined as weight reduction in pork samples during storage in a hermetically sealed container at a temperature of $8{ }^{\circ} \mathrm{C}$ for 24 hours. The moisture holding capacity was measured by the Grau and Hamm method in modification of VNIIMP. Arithmetic mean of three single measurements was taken as the final result.

The color of muscle tissue was determined in the CIELab color space using a spectrophotometer Konica Minolta CM-2300d. The color was measured at three points on the sample surface. Arithmetic mean of three single measurements was taken as the final result.

Statistical processing of the experimental data was carried out using Microsoft Excel 2010 and Statistica 10.0. Significance of differences between means that satisfied the conditions of normal distribution and equality of dispersion was assessed by one-way analysis of variance (ANOVA). The results were presented as $M_{\text {mean }}$ (weighted average of measured values) $\pm s$ (standard error of the mean).

\section{Results and discussion}

Hartung J. et al. [7] reported that the use of gas stunning at $90 \% \mathrm{CO}_{2}$ led to death of most animals before the beginning of bleeding. In our experiment, assessment of the condition of Large White pigs after gas stunning (Table 1) showed that 24 animals (65\% of total number) were stunned normally; that is, they did not demonstrated the signs of sensibility, but retained cardiac activity. In 11 pigs (30\%), the death was diagnosed as a result of absence of heart beat recorded by a pulse oximeter. In two animals (5\%), retention of sensibility was observed indicating an insufficient effect of $\mathrm{CO}_{2}$ stunning. Nevertheless, our results showed quite a high proportion of dead animals, which consequently can create problems regarding meat hygiene [7].

There is another approach to studying the physiological conditions of animals during gas stunning, which consists in registration and recording electroencephalograms (EEG) using special devices attached to animals. Special sensors register changes in brain activity including the onset of unconsciousness or death. However, implementation of this approach in the production conditions faces significant difficulties. It is necessary to shave animal heads beforehand in the areas of electrode fixation (the forehead part), attach belts with devices and wires to electrodes to animals and to train animals to wear them for several days $[7,8]$. Our approach 
Table 1. Assessment of the animal condition after gas stunning Assessment of the animal condition after stunning

\begin{tabular}{c|c} 
Presence (+) / & $\begin{array}{c}\text { Presence (+) / } \\
\text { absence (-) }\end{array}$ \\
$\dot{z}$ absence (-) \\
of heart beat & of sensibility signs
\end{tabular}

General conclusion about animal condition

\begin{tabular}{|c|c|c|c|}
\hline 1 & + & - & Norm \\
\hline 2 & - & - & Death \\
\hline 3 & + & - & Norm \\
\hline 4 & - & - & Death \\
\hline 5 & + & - & Norm \\
\hline 6 & + & - & Norm \\
\hline 7 & + & - & Norm \\
\hline 8 & + & - & Norm \\
\hline 9 & - & - & Death \\
\hline 10 & - & - & Death \\
\hline 11 & + & - & Norm \\
\hline 12 & + & - & Norm \\
\hline 13 & + & - & Norm \\
\hline 14 & + & - & Norm \\
\hline 15 & + & - & Norm \\
\hline 16 & + & - & Norm \\
\hline 17 & + & - & Norm \\
\hline 18 & + & - & Norm \\
\hline 19 & - & - & Death \\
\hline 20 & - & - & Death \\
\hline 21 & - & - & Death \\
\hline 22 & + & - & Norm \\
\hline 23 & + & - & Norm \\
\hline 24 & + & - & Norm \\
\hline 25 & - & - & Death \\
\hline 26 & - & - & Death \\
\hline 27 & + & - & Norm \\
\hline 28 & - & - & Death \\
\hline 29 & + & - & Norm \\
\hline 30 & + & - & Norm \\
\hline 31 & - & - & Death \\
\hline 32 & + & - & Norm \\
\hline 33 & + & - & Norm \\
\hline 34 & + & - & Norm \\
\hline 35 & + & - & Norm \\
\hline 36 & + & + & Retention of sensibility \\
\hline 37 & + & + & Retention of sensibility \\
\hline
\end{tabular}

based on measuring heart rate probably is less informative but simpler for implementation in production conditions. It is also necessary to note that in the experiment with EEG registration, which was carried out at $95 \% \mathrm{CO}_{2}$, all animals were dead over $5 \mathrm{~min}$. due to irreversibility of unconsciousness [8].

Based on the assessment results regarding the physiological conditions of 37 animals (Table 1), ten of them were selected by the method of random sampling including five pigs from normally stunned animals and five from dead animals. The results of the examination of the internal organs obtained as a result of evisceration of the carcasses from these animals are presented in Table 2.

As can be seen from Table 2, the internal organs from carcasses of normally stunned animals were filled with blood to the same (and even to a slightly higher) degree as the organs from the carcasses of the dead animals. This result was somewhat unexpected, as it was assumed that bleeding was more complete when cardiac activity was retained. However, the obtained data still give little grounds to state that cardiac arrest at stunning does not affect a degree of carcass bleeding.

The following results were obtained for ten carcasses selected for assessing the condition of the internal organs: $70 \%$ of hearts and $70 \%$ of lungs were characterized by the high degree of blood filling. With that, the high degree of blood filling was noted only for $30 \%$ of the liver samples. These results allow suggesting that cardiac arrest in animals could occur after pulse measurement but before the beginning of bleeding.

The hot carcass weight, $\mathrm{pH}$ value after $45 \mathrm{~min}\left(\mathrm{pH}_{1}\right)$ and 24 hours $\left(\mathrm{pH}_{24}\right)$ were measured for each of 37 carcasses (Table 3). By the results of $\mathrm{pH}_{1}$ measurement, PSE pork carcasses were selected, in which a $\mathrm{pH}$ value $45 \mathrm{~min}$. after slaughter was lower than 6.0, and pH24 was lower than 5.5. Carcasses that had only one low $\mathrm{pH}$ value $\left(\mathrm{pH} 1\right.$ or $\left.\mathrm{pH}_{24}\right)$ were classified as meat with signs of PSE.

As can be seen from Table 3, pork from animals without cardiac activity and pork from normally stunned animals practically did not differ by the mean values of $\mathrm{pH}$ after $45 \mathrm{~min}$. and 24 hours. However, carcasses of dead animals demonstrated higher inclination to the development of the PSE defect (36\% carcasses versus $25 \%$ ).

Table 2. Assessment of the condition of the internal organs

\begin{tabular}{|c|c|c|c|}
\hline \multirow{2}{*}{$\begin{array}{l}\text { No. of } \\
\text { animal }\end{array}$} & \multicolumn{3}{|c|}{ Assessment of the condition of the internal organs: } \\
\hline & heart & lung & liver \\
\hline \multicolumn{4}{|c|}{ Carcasses from normally stunned animals } \\
\hline 1 & Blood filling + & Blood filling + & Blood filling + \\
\hline 3 & Blood filling +++ , blood clots in cardiac & Blood filling +++ , hemoaspiration & Blood filling +++ \\
\hline 5 & Blood filling +++ , blood clots in cardiac & Blood filling +++ , hemoaspiration & Blood filling ++ \\
\hline 18 & Blood filling +++ , blood clots in cardiac & Blood filling +++ , hemoaspiration & Blood filling + \\
\hline 27 & Blood filling +++ , blood clots in cardiac & Blood filling +++ , hemoaspiration & Blood filling +++ \\
\hline \multicolumn{4}{|c|}{ Carcasses of animals, in which death was observed after gas stunning } \\
\hline 2 & Blood filling +++ , blood clots in cardiac & Blood filling ++ , hemoaspiration & Blood filling + \\
\hline 4 & Blood filling ++ & Blood filling + , hemoaspiration & Blood filling + \\
\hline 20 & Blood filling +++ , blood clots in cardiac & Blood filling +++ , hemoaspiration & Blood filling + \\
\hline 21 & Blood filling + & Blood filling +++ , hemoaspiration & Blood filling + \\
\hline 25 & Blood filling +++ , blood clots in cardiac & Blood filling +++, hemoaspiration & Blood filling +++ \\
\hline Designations: & $\begin{array}{ll}\text { Blood filling +: } & \text { norm or insignificant d } \\
\text { Blood filling ++: } & \text { medium degree of bloo } \\
\text { Blood filling +++: } & \text { medium degree of bloo }\end{array}$ & $\begin{array}{l}\text { od filling of tissues of the internal org } \\
\text { tissues of the internal organ; } \\
\text { tissues of the internal organ. }\end{array}$ & \\
\hline
\end{tabular}


Table 3. Hot carcass weight and pork $\mathrm{pH}$ value

\begin{tabular}{|c|c|c|c|c|}
\hline \multirow{2}{*}{$\begin{array}{l}\text { No of } \\
\text { animal }\end{array}$} & \multirow{2}{*}{$\begin{array}{c}\text { Hot carcass } \\
\text { weight }\end{array}$} & \multicolumn{2}{|c|}{ pH value } & \multirow{2}{*}{ Quality group } \\
\hline & & $\mathrm{pH}_{1}$ & $\mathrm{pH}_{24}$ & \\
\hline \multicolumn{5}{|c|}{ Carcasses from normally stunned animals } \\
\hline 1 & 69.8 & 6.10 & 5.62 & NOR \\
\hline 3 & 60.0 & 5.75 & 5.45 & PSE \\
\hline 5 & 66.4 & 6.16 & 5.43 & with signs of PSE \\
\hline 6 & 66.8 & 6.11 & 5.49 & with signs of PSE \\
\hline 7 & 70.2 & 6.12 & 5.53 & NOR \\
\hline 8 & 57.2 & 5.68 & 5.57 & PSE \\
\hline 11 & 58.8 & 5.87 & 5.54 & PSE \\
\hline 12 & 68.8 & 6.36 & 5.55 & NOR \\
\hline 13 & 61.8 & 5.97 & 5.43 & PSE \\
\hline 14 & 61.6 & 6.03 & 5.54 & NOR \\
\hline 15 & 68.6 & 6.07 & 5.90 & NOR \\
\hline 16 & 60.6 & 6.82 & 5.53 & NOR \\
\hline 17 & 56.6 & 6.02 & 5.74 & NOR \\
\hline 18 & 77.4 & 6.04 & 5.52 & NOR \\
\hline 22 & 75.8 & 6.01 & 5.57 & NOR \\
\hline 23 & 62,2 & 6,37 & 5.69 & NOR \\
\hline 24 & 56.0 & 6.49 & 5,59 & NOR \\
\hline 27 & 63.2 & 6.00 & 5.60 & NOR \\
\hline 29 & 63.8 & 6.24 & 5.55 & NOR \\
\hline 30 & 69.2 & 6.45 & 5.52 & NOR \\
\hline 32 & 56.6 & 6.15 & 5.64 & NOR \\
\hline 33 & 77.2 & 6.28 & 5.64 & NOR \\
\hline 34 & 63.8 & 6.32 & 5.65 & NOR \\
\hline 35 & 59.8 & 6.12 & 5.62 & NOR \\
\hline
\end{tabular}

\begin{tabular}{|l|l|l|l|} 
Mean value & $64.68 \pm 6.41$ & $6.15 \pm 0.25$ & $5.58 \pm 0.10$
\end{tabular}

Carcasses of animals, in which death was observed after gas stunning

\begin{tabular}{|c|c|c|c|c|}
\hline 2 & 63.2 & 6.34 & 5.52 & NOR \\
\hline 4 & 57.2 & 5.92 & 5.45 & PSE \\
\hline 9 & 77.6 & 5.31 & 5.49 & PSE \\
\hline 10 & 53.4 & 5.42 & 5.53 & PSE \\
\hline 19 & 66.2 & 6.15 & 5.52 & NOR \\
\hline 20 & 74.2 & 6.07 & 5.63 & NOR \\
\hline 25 & 74.4 & 6.30 & 5.48 & with signs of PSE \\
\hline 26 & 68.8 & 6.22 & 5.75 & NOR \\
\hline 28 & 88.4 & 6.05 & 5.62 & NOR \\
\hline 31 & 61.0 & 6.38 & 5.60 & NOR \\
\hline
\end{tabular}

\begin{tabular}{l|l|l|l|} 
Mean value & $67.05 \pm 10.97$ & $6.05 \pm 0.38$ & $5.57 \pm 0.09$
\end{tabular}

There is an opinion regarding pork that $\mathrm{CO}_{2}$-stunning does not provoke glycogen breakdown and consequently $\mathrm{pH}$ drop [9]. Other studies allowed making a opposite conclusions. For instance, it was shown by the example of turkey that $\mathrm{CO}_{2}$ - stunning can lead to meat with lower $\mathrm{pH}$ compared to electrical stunning [10].

Mota-Rojas D. et al. rightly indicate that when $\mathrm{CO}_{2}$ is respired, it combines with water with the development of $\mathrm{H}_{2} \mathrm{CO}_{3}$ (carbonic acid), which generates high concentrations of $\mathrm{H}+$ ions resulting in the state of acidosis on the cellular level. Inhalation of high $\mathrm{CO}_{2}$ concentrations can cause distress in animals (a negative form of stress) before they become unconscious. Pigs exposed to $\mathrm{CO}_{2}$ experience respiratory and metabolic acidosis. The blood level of lactate, which is an indicator of stress, increases. An increase in the lactate level can be linked with stress factors before slaughter (for example, aggressive handling immediately before stunning) and negatively affect pork quality [11].

In our experiment, animal death upon stunning can be explained by their individual characteristics and higher susceptibility to stress. This, in turn, can provoke an appearance of a higher number of PSE carcasses from animals with cessation of cardiac activity.

A result of pig stunning can depend on their weight. In our experiment, there was no possibility to measure the animal live weight and/or weight after stunning; therefore, we compared two animal groups by the hot carcass weight. The mean value of the hot carcass weight from dead animals was slightly higher than those from normally stunned animals $(67.05 \mathrm{~kg}$ and $64.68 \mathrm{~kg}$, respectively). However, the result of Student's t-test calculation showed that differences of the mean values of the carcass weight were not statistically significant $(t=0.17, p=0.853$, the critical value of Student's t-test $=2.035$ at the significance level $\alpha=0.05$ ).

There were only two animals in the experiment that retained sensibility. An average weight of hot carcasses of these animals was $79.5 \pm 2.4 \mathrm{~kg}$. A test of the hypothesis about the difference in the carcass weight between these animals and animals that were normally stunned showed that the differences were statistically significant $(t=2.14$, $p=0.043$, the critical value of Student's t-test $=2.064$, at the significance level $\alpha=0.05$ ). However, due to insignificance of sampling $(n=2)$, conclusions about an effect of increased weight of Large White pigs on retention of sensibility upon gas stunning would be premature and require a set of larger volumes of experimental data.

Statistical data analysis did not reveal correlation between the hot carcass weight and $\mathrm{pH}$ values.

Functional-technological indicators of meat quality and color characteristics (Table 4) were investigated randomly on the samples from ten carcasses selected in a random manner. Statistical analysis using Student's t-test did not reveal significant differences between pork obtained from normally stunned and dead animals. The mean values of moisture holding capacity (MHC) were $74.75 \%$ and $74.71 \%$, drip losses were $6.50 \%$ and $6.19 \%$, respectively, for the samples from the carcasses of normally stunned and dead animals. The samples also did not differ by the mean values of moisture mass fraction $(74.75 \%$ and $74.71 \%$, respectively).

By color characteristics, pork from Large White pigs was characterized by quite high values of lightness $\left(\mathrm{L}^{*}\right)$ and low values of redness $\left(\mathrm{a}^{*}\right)$; although when using $\mathrm{CO}_{2}$ stunning, pork usually has darker color [9]. The differences in color between pork samples from normally stunned and dead animals were also not established. 
Table 4. Pork functional-technological indicators and color

\begin{tabular}{|c|c|c|c|c|c|c|}
\hline \multirow{2}{*}{ No. of animals } & \multirow{2}{*}{ Drip losses, \% } & \multirow{2}{*}{ MHC, \% } & \multirow{2}{*}{ Moisture, \% } & \multicolumn{3}{|c|}{ Color characteristics } \\
\hline & & & & $\mathbf{L}$ & a & b \\
\hline \multicolumn{7}{|c|}{ Carcasses from normally stunned animals } \\
\hline 1 & 4.77 & 55.64 & 73.29 & 48.19 & 3.72 & 8.34 \\
\hline 3 & 5.95 & 55.77 & 74.51 & 55.17 & 2.41 & 8.35 \\
\hline 5 & 5.66 & 53.06 & 75.37 & 55.75 & 3.94 & 8.60 \\
\hline 18 & 8.34 & 54.01 & 75.4 & 53.10 & 4.00 & 7.57 \\
\hline 22 & 7.80 & 49.38 & 75.2 & 59.05 & 2.45 & 8.50 \\
\hline Mean value & $6.50 \pm 1.51$ & $53.57 \pm 2.60$ & $74.75 \pm 0.89$ & $54.25 \pm 4.01$ & $3.30 \pm 0.80$ & $8.27 \pm 0.41$ \\
\hline \multicolumn{7}{|c|}{ Carcasses of animals, in which death was observed after gas stunni } \\
\hline 2 & 5.50 & 55.00 & 74.37 & 55.20 & 2.75 & 8.13 \\
\hline 4 & 5.80 & 55.96 & 74.47 & 53.90 & 2.86 & 8.45 \\
\hline 19 & 5.21 & 50.10 & 73.42 & 55.14 & 2.81 & 7.84 \\
\hline 20 & 7.27 & 54.83 & 75.48 & 58.23 & 1.95 & 7.52 \\
\hline 21 & 7.15 & 53.48 & 75.81 & 56.71 & 1.80 & 8.00 \\
\hline Mean value & $6.19 \pm 0.96$ & $53.87 \pm 2.29$ & $74.71 \pm 0.95$ & $55.84 \pm 1.67$ & $2.43 \pm 0.51$ & $7.99 \pm 0.34$ \\
\hline
\end{tabular}

\section{Conclusion}

By the results of the performed work, the further study on an effect of $\mathrm{CO}_{2}$-stunning on quality of pork from Russian pig breeds is considered an important task, including the aspects of animal welfare monitoring in national enterprises. The results of the research show that regarding Large White pigs, up to $5 \%$ of animals (especially larger animals) can retain signs of sensibility at $90 \%$ gas concentration and exposure duration of $115 \mathrm{sec}$. Five percent of animals is a good result. For example, studies carried out in different German enterprises demonstrated that $6.2-17.1 \%$ of pigs retained corneal reflex [12].
Detection of presence/ absence of cardiac activity using a pulse oximeter is a convenient method for controlling an animal condition upon unloading from a stunning chamber, which is feasible for using in the work of a production line. Using a pulse oximeter, cessation of cardiac activity was recorded in 30\% of animals. However, cardiac arrest practically did not influence either a degree of the internal organ bleeding or meat quality including meat color characteristics. Obviously, it is necessary to control presence/ absence of the pulse and signs of sensibility immediately before bleeding to obtain more objective picture of physiological conditions of animals.
1. COUNCIL REGULATION (EC) No 1099/2009 of 24 September 2009 on the protection of animals at the time of killing [Electronic resource: https://eur-lex.europa.eu/LexUriServ/LexUriServ.do?uri = 0J: L:2009:303:0001:0030: EN: PDF Access date 20.03.2020]

2. EFSA Panel on Animal Health and Welfare (AHAW) (2013). Scientific Opinion on monitoring procedures at slaughterhouses for pigs. EFSA Journal, 11(12). https://doi.org/10.2903/j. efsa.2013.3523

3. European Food Safety Authority (EFSA) (2004). Opinion of the Scientific Panel on Animal Health and Welfare (AHAW) on a request from the Commission related to welfare aspects of the main systems of stunning and killing the main commercial species of animals. EFSA Journal, 2(7), 45. (2004), 45. https://doi. org/10.2903/j.efsa.2004.45

4. Lisitsyn, A.B., Lipatov, N.N., Kudryashov, L.S., Aleksakhina, V.A., Chernukha, I.M. (2004). Theory and Practice of Meat Processing. Moscow: VNIIMP. -378 p. ISBN: 5-901768-14-0 (In Russian)

5. Semenova A. A., Mittelshtein T. M., Kozyrev I. V. (2016). Conditions of livestock transportation and pre-slaughter handling as factors forming meat quality. Vsyo myase, 2,42-47. (In Russian) 6. Chistyakov, V.T. (2018). Modern development of breeding and genetics in the Russian pig breeding. Vestnik of Voronezh State Agrarian University, 4(59), 71-78. https://doi.org/10.17238/ issn2071-2243.2018.4.71 (In Russian)

7. Hartung, J., Nowak, B., Waldmann, K.H., Ellerbrock, S. (2002). $\mathrm{CO}_{2}$-stunning of slaughter pigs: effects on EEG, catecholamines and clinical reflexes. Deutsche tierarztliche Wochenschrift, 109(3),135-139. PMID: 11963365

8. Verhoeven, M., Gerritzen, M., Velarde, A., Hellebrekers, L., Kemp B. (2016). Time to Loss of Consciousness and Its Relation to Behavior in Slaughter Pigs during Stunning with 80 or $95 \%$ Carbon Dioxide. Frontiers in Veterinary Science, 3, 38. https://doi. org/10.3389/fvets.2016.00038

9. Marcon, A.V., Caldara, F.R., de Oliveira, G. F., Gonçalves, L.M.P., Garcia R. G., Paz, I.C.L.A., Crone, C., Marcon, A. (2019). Pork quality after electrical or carbon dioxide stunning at slaughter. Meat Science, 156, 93-97. https://doi.org/10.1016/j.meatsci.2019.04.022

10. Fleming, B.K., Froning, G.W., Beck, M.M., Sosnicki, A.A. (1991). The Effect of Carbon Dioxide as a Preslaughter Stunning Method for Turkeys. Poultry Science, 70(10), 2201-2206. https://doi.org/10.3382/ps.0702201

11. Mota-Rojas, D., Bolaños-Ló, D., Concepcion, M., RamirezTe, J., Roldan-San, P., Flores-Pei, S., Mora-Medin, P. (2012). Stunning Swine with $\mathrm{CO}_{2}$ Gas: Controversies Related to Animal Welfare. International Journal of Pharmacology, 8(3), 141-151. https://doi.org/10.3923/ijp.2012.141.151

12. Fries, R., Rindermann, G., Siegling-Vlitakis, C., Bandick, N., Bräutigam, L., Buschulte, A., Irsigler, H., Wolf, K., H. Hartmann, H. (2013). Blood parameters and corneal-reflex of finishing pigs with and without lung affections observed post mortem in two abattoirs stunning with $\mathrm{CO}_{2}$. Research in Veterinary Science, 94(1), 186-190. https://doi.org/10.1016/j. rvsc.2012.07.022 


\section{AUTHOR INFORMATION}

Anastasia A. Semenova - doctor of technical sciences, professor, Deputy Director, V. M. Gorbatov Federal Research Center for Food Systems of Russian Academy of Sciences. 109316, Moscow, Talalikhina str., 26. Tel: +7-903-016-76-70. E-mail: a.semenova@fncps.ru ORCID: http://orcid.org/0000-0002-4372-6448

Alena I. Sinichkina - junior research scientist, Department of applied scientific and technological development, V. M. Gorbatov Federal Research Center for Food Systems of Russian Academy of Sciences. 109316, Moscow, Talalikhina str., 26. Tel: +7-495-676-97-71. E-mail: a.sinichkina@fncps.ru

ORCID: https://orcid.org/0000-0002-0410-0012

Ilya V. Kozyrev - candidat of technical sciences, leading research scientist, Department of applied scientific and technological development, V. M. Gorbatov Federal Research Center for Food Systems of Russian Academy of Sciences. 109316, Moscow, Talalikhina str., 26. Tel: +7-495676-97-71.E-mail: i.kozyrev@fncps.ru ORCID: https://orcid.org/0000-0001-8135-7869

Tatyana M. Mittelstein - senior research scientist, Department of applied scientific and technological development, V. M. Gorbatov Federal Research Center for Food Systems of Russian Academy of Sciences. 109316, Moscow, Talalikhina str., 26. Tel: +7-495-676-97-71. E-mail: t.mittelshtein@fncps.ru

ORCID: https://orcid.org/0000-0001-8053-2848

All authors bear responsibility for the work and presented data.

All authors made an equal contribution to the work.

The authors were equally involved in writing the manuscript and bear the equal responsibility for plagiarism.

The authors declare no conflict of interest.

Received 19.04.2020 Accepted in revised 18.06. 2020 Accepted for publication 25.06.2020 